\title{
REVISED Alanylated lipoteichoic acid primer in Bacillus subtilis
}

\section{[version 2; peer review: 2 approved]}

\author{
Yu Luo (iD \\ Department of Biochemistry, University of Saskatchewan, Saskatoon, Canada
}

V2 First published: 10 Feb 2016, 5:155

https://doi.org/10.12688/f1000research.8007.1

Latest published: $11 \mathrm{Apr} 2016, \mathbf{5 : 1 5 5}$

https://doi.org/10.12688/f1000research.8007.2

\section{Abstract}

Lipoteichoic acid is a major lipid-anchored polymer in Gram-positive bacteria such as Bacillus subtilis. This polymer typically consists of repeating phosphate-containing units and therefore has a predominant negative charge. The repeating units are attached to a glycolipid anchor which has a diacylglycerol (DAG) moiety attached to a dihexopyranose head group. D-alanylation is known as the major modification of type I and type IV lipoteichoic acids, which partially neutralizes the polymer and plays important roles in bacterial survival and resistance to the host immune system. The biosynthesis pathways of the glycolipid anchor and lipoteichoic acid have been fully characterized. However, the exact mechanism of D-alanyl transfer from the cytosol to cell surface lipoteichoic acid remains unclear. Here I report the use of mass spectrometry in the identification of possible intermediate species in the biosynthesis and D-alanylation of lipoteichoic acid: the glycolipid anchor, nascent lipoteichoic acid primer with one phosphoglycerol unit, as well as mono- and dialanylated forms of the lipoteichoic acid primer. Monitoring these species as well as the recently reported D-alanyl-phosphatidyl glycerol should aid in shedding light on the mechanism of the D-alanylation pathway of lipoteichoic acid.

\section{Keywords}

Host immune response, Gram-positive, Lipoteichoic acid, Dalanylation, Glycolipid D-alanyl-phosphatidylglycerol , Surface charge , Lipoteichoic acid primer, Mass spectrometry, Lipidomics 


\section{Associated Research Article}

Atila M and Luo Y » Profiling and tandem mass spectrometry analysis of aminoacylated phospholipids in Bacillus subtilis , F1000Research 2016, 5:121 (https://doi.org/10.12688/f1000research.7842.2)

Corresponding author: Yu Luo (yu.luo@usask.ca)

Competing interests: No competing interests were disclosed.

Grant information: This work is supported by Saskatchewan Health Research Foundation Group Grant (2008-2010) and Phase 3 Team Grant (2010-2013) to the Molecular Design Research Group at University of Saskatchewan, a Natural Sciences and Engineering Research Council Discovery Grant (2010-2015) 261981-2010 to YL.

The funders had no role in study design, data collection and analysis, decision to publish, or preparation of the manuscript.

Copyright: $\odot 2016$ Luo Y. This is an open access article distributed under the terms of the Creative Commons Attribution License, which permits unrestricted use, distribution, and reproduction in any medium, provided the original work is properly cited. Data associated with the article are available under the terms of the Creative Commons Zero "No rights reserved" data waiver (CC0 1.0 Public domain dedication).

How to cite this article: Luo Y. Alanylated lipoteichoic acid primer in Bacillus subtilis [version 2; peer review: 2 approved] F1000Research 2016, 5:155 https://doi.org/10.12688/f1000research.8007.2

First published: 10 Feb 2016, 5:155 https://doi.org/10.12688/f1000research.8007.1 


\section{REVISED Amendments from Version 1}

All abbreviation "Pho" for phosphate are replaced with "P". All abbreviation "LTA" for lipoteichoic acid primer are replaced with "LTAP".

The chemical structures in Figure 1 and Figure 5 are redrawn to show double bond in the same thickness and glucosyl residues in their chair conformation.

Type I teichoic acids in B. subtilis as well as other four types of teichoic acids are mentioned. Type I and type IV teichoic acids undergo D-alanylation.

In the abstract, it becomes "in the identification of possible intermediate species".

In the abstract, "would aid in" becomes "should aid in".

In the introduction, lipid A and lipopolysaccharide as well as the outer membrane of Gram-negative bacteria has been mentioned

In the discussion, abundance of D-alanine over L-alanine in the lipid lysate is discussed.

The word "adenylation" is replaced with "adenylylation".

In the introduction, "DltB is predicted to be an integral membrane protein".

The name "o-acyltransferase" becomes "O-acyltransferace".

In figure legends, "aicd" has been corrected as "acid".

"FA - fatty acid" has been added to the notes of Table 2, Table 3 and Table 4.

"The smaller 1017 amu anion" becomes "The 1017 amu anion".

See referee reports

\section{Introduction}

Phospholipids are the dominant cell membrane component in most bacteria $^{1}$ which render bacterial cell surface negatively charged. This feature makes bacterial membrane the easy target of host immune molecules such as cationic antibiotic peptides ${ }^{2-4}$. Bacteria have been known to constantly modulate membrane components ${ }^{1,5}$. There are at least three pathways which may contribute to surface charge modulation: biosynthesis of phosphatidylethanolamine (PE), L-lysyl-phosphatidylglycerol (lysyl-PG), and D-alanylation of lipo- and wall-teichoic acids. In comparison with Gram-negative bacteria, Gram-positive bacteria typically have noticeably less $\mathrm{PE}^{1}$, but have an abundance of lysyl-PG or other aminoacylated PGs which most Gram-negative bacteria lack ${ }^{5,6}$. Besides, lipo- and wall-teichoic acids are only found in Gram-positive bacteria.

Gram-positive bacteria lack the outer membrane as well as phosphate-rich lipid A and lipopolysaccharide found in Gram-negative bacteria. Instead they have a diverse category of polymeric teichoic acids made of phosphate-containing repeating units. Peptidoglycanattached wall-teichoic acids and glycolipid-anchored lipoteichoic acids were discovered six decades ago ${ }^{7}$. There are five types of lipoteichoic acids ${ }^{10}$ and four types of wall teichoic acids ${ }^{11}$. The biosynthesis pathways of the two types of teichoic acids have been characterized $^{8-11}$. Glycerol or ribitol residues in the repeating units of type I and type IV lipoteichoic acids ${ }^{10}$ as well as type I wall teichoic acids $^{11}$ are known to undergo D-alanine esterification ${ }^{7,9,12}$, which is known to be carried out by the four $d l t$ operon-coded proteins
DltABCD ${ }^{13}$. This surface charge modulation has been observed to significantly affect the antigenicity of the bacteria ${ }^{2}$. In the cytosol, DltA ( 500 amino acid residues) catalyzes with the consumption of ATP first the adenylylation of D-alanine and then the thioester formation with D-alanyl-carrier protein DltC ( 80 amino acids $)^{13-15}$. Crystal structures of DltA ${ }^{16,17}$ have proven that DltA is homologous to adenylation domains (also called AMP-forming domains) found in modular nonribosomal peptide synthetases ${ }^{18}$ as well as fatty acylcoenzyme A synthetases ${ }^{19}$ and firefly luciferases ${ }^{20}$. The functionally uncharacterized DltB ( 400 amino acid residues) is predicted to be an integral membrane protein with multiple putative transmembrane helices with a low level of similarity to a putative group of membrane-bound O-acyltransferases ${ }^{21}$. DltD ( 400 amino acid residues), with a single putative $\mathrm{N}$-terminal transmembrane helix and a large globular domain, has been reported to bind DltC and possibly catalyzes the final D-alanyl transfer from DltC to teichoic acid ${ }^{22}$. We have recently characterized the presence of D- but not L-alanine in lipid lysate from Bacillus subtilis, implying the presence of D-alanyl-PG in the bacterial membrane ${ }^{23}$. Observation of other D-alanylated species in the bacterial membrane would help sketching a transfer route for the D-alanyl group from inside the cytosol to teichoic acids on the outer surface. Here I report profiling of B. subtilis lipids and identification of mono- and di-alanylated derivatives of nascent lipoteichoic acid primer with a single phosphoglycerol unit attached to the glycolipid anchor (chemical structures shown in Figure 1).

\section{Materials and methods}

Bacterial strain and cell culture. The BL21 (DE3) strain of E. coli (Novagen) and B. subtilis strain 168 (Bacillus Genetic Stock Center) were first plated from freezer stock onto LB-agar media. A single colony was transferred into $100 \mathrm{ml}$ of LB media. After incubation overnight at $37^{\circ} \mathrm{C}$ and $220 \mathrm{rpm}$ in an environmental shaker, it was transferred to 1 liter of LB media. When the cell density reached $\sim 1.0$ at $600 \mathrm{~nm}, 200 \mathrm{ml}$ cell culture supplemented with $2.0 \mathrm{ml}$ of $1.0 \mathrm{M} \mathrm{NaAc}$ buffer at $\mathrm{pH} 4.6$ was centrifuged at 5,500 rpm in a Beckman JLA-8.1 rotor for 16 minutes at $4^{\circ} \mathrm{C}$. The wet cell pellet was used for lipid extraction.

Lipid extraction. HPLC-grade organic solvents (Fisher Scientific) and distilled and deionized water were used throughout the experiment. The lipid extraction procedure was following that of Bligh and Dyer ${ }^{24}$. Briefly, the wet cell pellet was re-suspended in a glass tube in $0.5 \mathrm{ml}$ ice-chilled water and $2.0 \mathrm{ml}$ of ice-chilled methanol. Then $1.0 \mathrm{ml}$ of cold chloroform was added. The suspension was vortexed for 3 seconds every 5 minutes and incubated on ice for a duration of 10 minutes. After that, $2.0 \mathrm{ml}$ cold chloroform was added followed by $1.5 \mathrm{ml}$ of cold water. The tube was vortexed for 3 seconds and placed on a rocking platform at a room temperature of $21^{\circ} \mathrm{C}$ for 3 minutes. Phase separation was assisted by centrifugation at 1,300 rpm for 5 minutes with a Beckman Allegro X-22R centrifuge. The heavier chloroform-rich phase was transferred by a glass syringe to a second glass centrifuge tube. Another $2.0 \mathrm{ml}$ cold chloroform was added to the first tube and vortexed for 3 seconds. Then the first tube was put back on the rocking platform at room temperature for 10 minutes. Centrifugation at 1,300 rpm for 5 minutes and transfer of the heavier chloroform-rich phase to the second glass tube followed. The combined chloroform-rich phase was 

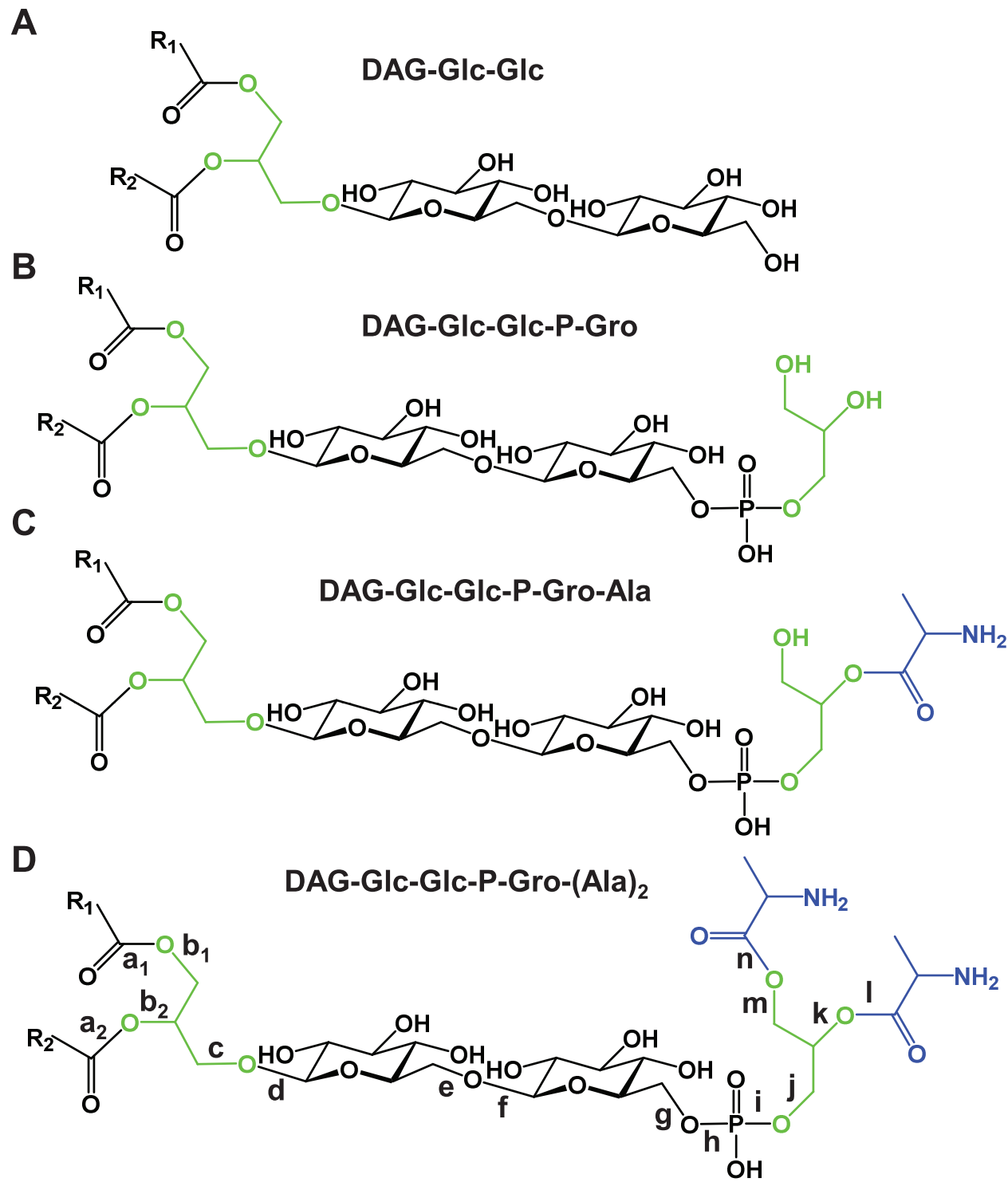

Figure 1. Molecular structures. Scissile bonds are labeled alphabetically in D. DAG - diacylglycerol; P - phosphate; Gro - glycerol; Glc-glucose; Ala - alanine. A. The glycolipid anchor of lipoteichoic acid: DAG-Glc-Glc. B. The lipoteichoic acid primer: DAG-Glc-Glc-P-Gro. C. Mono-alanylated lipoteichoic acid primer: DAG-Glc-Glc-P-Gro-Ala. D. Bis-alanylated lipoteichoic acid primer: DAG-Glc-Glc-P-Gro-(Ala),

mixed with $0.5 \mathrm{ml} 0.5 \mathrm{M} \mathrm{NaCl}$, vortexed for 3 seconds and gentle shaking by hand for 1 minute. After centrifugation at 1,300 rpm for 5 minutes, the chloroform-rich phase, $4.0-4.5 \mathrm{ml}$ in volume, was collected in a third glass tube for storage at $-80^{\circ} \mathrm{C}$. Typically, the total lipid concentration was estimated as $0.5 \mathrm{mg} / \mathrm{ml}$.

Lipid profiling by mass spectroscopy. The lipid samples were diluted by adding 2 -fold volume of methanol to a concentration of $\sim 0.15 \mathrm{mg} / \mathrm{ml}$ (or $150 \mathrm{ppm}$ ) for direct infusion at a rate of $0.6 \mathrm{ml} / \mathrm{hour}$ to a SCIEX 4000 QTRAP mass spectrometer. Electrospray ionization was achieved at a temperature of $500^{\circ} \mathrm{C}$ and a pressure of 20 psi for curtain gas as well as ion source gas 1 and 2 . The collision energy in the ion trap was tested between 30 and 100 electronvolts for most efficient detection of target substructures in the lipids. The SCIEX Analyst 1.6 software was used to acquire and export averaged mass spectra with the 4000 QTRAP system. Agilent MassHunter B.06.00 was used to process mass spectra with an Agilent Q-TOF 6500 system. MS spectra in the figures were also analyzed with Mass++ 2.7.4 software ${ }^{25}$ and presented with Microsoft Excel.

Tandem mass spectroscopy. The targeted MS/MS spectra were first acquired using the SCIEX 4000 QTRAP system with multiple collision energy settings between 50 and 90 electronvolts. Highaccuracy MS/MS spectra were acquired using the Agilent Q-TOF 
6550 system with collision energy ranging from 30 to 80 electronvolts. Direct infusion was also employed but at a faster flow rate of $2.0 \mathrm{ml} /$ hour for the Q-TOF 6550 system.

\section{Results}

Dataset 1. Raw data for 'Alanylated lipoteichoic acid primer in Bacillus subtilis', Luo 2016

http://dx.doi.org/10.5256/f1000research.8007.d113434

README.txt contains a description of the files.

Polar lipid extraction on ice produced more species in the sample Ice-chilled solvents instead of room-temperature ones were used during the well-established polar lipid extraction procedure devised by Bligh and Dyer ${ }^{24}$. The new lipid preparations did not show marked differences on thin-layer chromatograms. However, their mass spectra showed noticeable difference with the cold extraction producing more species than room-temperature extraction. The alanylated derivatives of lipoteichoic acid primer were not observed in lipids extracted at room temperature.

Profiling and tandem mass spectroscopy of polar lipids with dihexose head group - The sodiated form of the lipid anchor of lipoteichoic acid in B. subtilis has been identified by mass spectrometry previously ${ }^{26}$. Several mass spectrometric scans with the 4000 QTRAP system in search for the lipid anchor were experimented. The anchor has a common structure of DAG-dihexose, with the hexose being either glucose or galactose depending on the identity of the microbial organism ${ }^{27}$. The unbranched and typically glycerolphosphate polymer is attached to C-6 of the non-reducing hexopyranosyl end of the glycolipid anchor by a phosphodiester bond $^{27}$. In B. subtilis, the head group is diglucose ${ }^{27}$ (Figure 1A). The sodiated dehydrated diglucose $(342-18+23=347 \mathrm{amu})$ at a collision energy of +80 electronvolts revealed the two most intense peaks (887 and $915 \mathrm{amu}$ ) matching expected sizes of the lipid anchor with the two dominant fatty acyl compositions of (30:0) and (32:0), respectively ${ }^{26}$ (Figure 2A). Tandem mass spectra of the most abundant 915 amu species was then acquired with the SCIEX 4000 QTRAP system (Figure 2B) and the Agilent Q-TOF 6550 system (Table 1). The QTRAP system produced less noisy spectra which are shown in Figure 2-Figure 4. The $\mathrm{m} / \mathrm{z}$ values obtained from the Q-TOF system were more accurate and are listed in Table 1-Table 4. The observed molecular mass 915.601 closely matched the calculated value of 915.603 for (32:0) [DAG-Glc-Glc $+\mathrm{Na}]^{+}$. All the observed fragment ions also had their $\mathrm{m} / \mathrm{z}$ values within $0.002 \mathrm{amu}$ of calculated monoisotopic masses. The molecular ion dissociated to form two most abundant fragments at 645 and $673 \mathrm{amu}$, corresponding to neutral loss of (17:0) fatty acid (270 amu) and (15:0) fatty acid (242 amu), respectively. The two fatty acids have been known as the dominant ones in B. subtilis lipids ${ }^{23}$. The $753 \mathrm{amu}$ fragment ion corresponding to a neutral loss of a dehydrated glucose residue (162 amu) was less abundant than the twin peaks. Another set of twin peaks at 483 and 511 amu corresponded to neutral losses of the terminal glucose residue (162 amu) and either of the two fatty acids ( 270 and 242 amu respectively). The peak at 405 amu corresponded to the sodiated diglucose head group covalently linked with the didehydroxyl residue of glycerol $\mathrm{CH} 2=\mathrm{CH}-\mathrm{CH} 2-\mathrm{Glc}-\mathrm{Glc}$ (Table 1). The twin peaks at 365 and 347 amu corresponded to the sodiated diglucose head group and its dehydrated form, respectively. It is worth noting that the signature $[\mathrm{DAG}-\mathrm{OH}]^{+}$ion (551 amu) for glycerolphospholipids was missing. However, the two [MAG - OH] ${ }^{+}$ions at 299 and 327 amu were observed at lower intensity. Even though the 405 amu ion was more intense than the 347 ion, lipid profiling by searching for precursors of the $405 \mathrm{amu}$ cation was inferior to the precursor scan for the 347 amu cation.

Profiling and tandem mass spectrometry of lipids with phosphoglycerol terminus - The phosphoglycerol head group has a molecular mass of 172 and produced a cyclic, equivalent to dehydrated, residual anion at $153 \mathrm{amu}$. The $153 \mathrm{amu}$ fragment peak is most intense for phospholipids with a terminal phosphoglycerol, and weak for phospholipids - such as cardiolipin (CL) and aminoacylated PGs with such an embedded group. This scan between 400 and $1700 \mathrm{amu}$ at a collision energy of -95 electronvolts was most effective in hitting larger precursor ions (part of the mass range is shown in Figure $3 \mathrm{~A}$ ). The spectrum revealed a cluster of cardiolipin (CL) double anions in the 650-680 amu range and a more intense cluster centered around two major anions at 693 and $721 \mathrm{amu}$, corresponding to the dominant lipids of (30:0) and (32:0) PGs, respectively. There was an 887 amu unknown species as well as mostly dehydrated lysocardiolipins (lyso-CL) close to $1100 \mathrm{amu}$ and cardiolipins close to $1300 \mathrm{amu}$. There were no noticeable hits below $600 \mathrm{amu}$ or between 1400 and 1700 amu. Besides, the $1017 \mathrm{amu}$ and $1045 \mathrm{amu}$ anions matched expected masses of lipoteichoic acid primer (Figure 1B) with dominant fatty acyl compositions of (30:0) and (32:0), respectively.

The $1017 \mathrm{amu}$ anion had two identical (15:0) fatty acyl chains and therefore made assignment of fragments less difficult. The MS/ MS spectra of the 1017 ion acquired with the QTRAP system at a collision energy of -90 electronvolts is shown in Figure 3B, and $\mathrm{m} / \mathrm{z}$ values of fragments are listed in Table 2 . In addition to the 79 amu phosphate residue, the pair of $153 \mathrm{amu}$ and $171 \mathrm{amu}$ ions which corresponded to glycerolphosphate residue, the dominant fatty acid ion at 241 amu matched the expected (15:0) composition. Fragmentation at the two glycosyl bonds likely produced the $315 \mathrm{amu}$ and $477 \mathrm{amu}$ ions. At the other end of the spectrum, the $943 \mathrm{amu}$ ion was likely due to the neutral loss of cycloglycerol (74 amu). A further loss of (15:0) fatty acid (242 amu) or ketene (224 amu) likely produced the pair of 701 and 719 amu ions, respectively. Another pair at 775 and 793 amu were produced similarly but from the molecular ion. The 1017 amu molecular ion matched structural characteristics of a lipoteichoic acid primer with a single glycerolphosphate unit attached to the lipid anchor of diglucosyldiacyglycerol.

Profiling of lipids with ester-linked alanine - In negative mode, ester-linked fatty acids are known to form intense fragment [FA-H] ions. This is also true for ester-linked amino acids ${ }^{23}$. A precursor scan between 400 and $1700 \mathrm{amu}$ at an optimized collision energy of -95 electronvolts for $88 \mathrm{amu}$ [Alanine- $\mathrm{H}]^{-}$(part of the mass range is shown in Figure 4A) revealed as expected a cluster of alanylPGs with two dominant peaks at 764 and 792 amu corresponding to (30:0) and (32:0) alanyl-PG, respectively. The precursor scan also revealed two adjacent clusters of alanylated lipids separated by $71 \mathrm{amu}$ which corresponded to the molecular mass of a dehydrated alanine. The first cluster with dominant 1088 and $1116 \mathrm{amu}$ anions matched expected $\mathrm{m} / \mathrm{z}$ values of mono-alanylated lipoteichoic acid 
Table 1. Accurate masses of fragments from (32:0) [DAG-GIc-Glc $+\mathrm{Na}]^{+}$.

\begin{tabular}{|l|l|l|l|}
\hline Observed mass & Calculated mass & Cleavage & Description \\
\hline 299.2568 & 299.2588 & $\mathrm{a}_{1} \& \mathrm{c}$ & $(15: 0) \mathrm{MAG}-\mathrm{OH}$ \\
\hline 327.2885 & 327.2901 & $\mathrm{a}_{2} \& \mathrm{c}$ & $(17: 0) \mathrm{MAG}-\mathrm{OH}$ \\
\hline 347.0944 & 347.0955 & $\mathrm{~d}$ & Glc-Glc $-\mathrm{H}_{2} \mathrm{O}+\mathrm{Na}^{+}$ \\
\hline 365.1056 & 365.1060 & $\mathrm{c}$ & Glc-Glc $+\mathrm{Na}^{+}$ \\
\hline 405.1360 & 405.1374 & $\mathrm{~b}_{1} \& \mathrm{~b}_{2}$ & $\mathrm{CH}_{2}=\mathrm{CH}-\mathrm{CH}_{2}-\mathrm{Glc}-\mathrm{Glc}+\mathrm{Na}^{+}$ \\
\hline 483.2907 & 483.2936 & $\mathrm{~b}_{1} \& f$ & $(15: 0) \mathrm{MAG}-\mathrm{Glc}-\mathrm{H}_{2} \mathrm{O}+\mathrm{Na}^{+}$ \\
\hline 511.3233 & 511.3249 & $\mathrm{~b}_{2} \& f$ & $(17: 0) \mathrm{MAG}-\mathrm{Glc}-\mathrm{H}_{2} \mathrm{O}+\mathrm{Na}^{+}$ \\
\hline 645.3448 & 645.3464 & $\mathrm{~b}_{1}$ & $(15: 0) \mathrm{MAG}-\mathrm{Glc}-\mathrm{Glc}-\mathrm{H}_{2} \mathrm{O}+\mathrm{Na}^{+}$ \\
\hline 673.3760 & 673.3777 & $\mathrm{~b}_{2}$ & $(17: 0) \mathrm{MAG}-\mathrm{Glc}-\mathrm{Glc}-\mathrm{H}_{2} \mathrm{O}+\mathrm{Na}^{+}$ \\
\hline 753.5487 & 753.5496 & $f$ & $(32: 0) \mathrm{DAG}-\mathrm{Glc}+\mathrm{Na}^{+}$ \\
\hline 915.6005 & 915.6025 & {$[\mathrm{M}+\mathrm{Na}]^{+}$} & $(32: 0) \mathrm{DAG}-\mathrm{Glc}-\mathrm{Glc}+\mathrm{Na}^{+}$ \\
\hline
\end{tabular}

Note: The alphabetically labeled scissile bonds are shown in Figure 1D. P - phosphate; Gro - glycerol; MAG - monoacylglycerol; DAG - diacylglycerol; Glc - glucose. There are equivalent choices such as between $a_{1}$ and $a_{2}$, as well as between $b_{1}$ and $b_{2}$.

A.

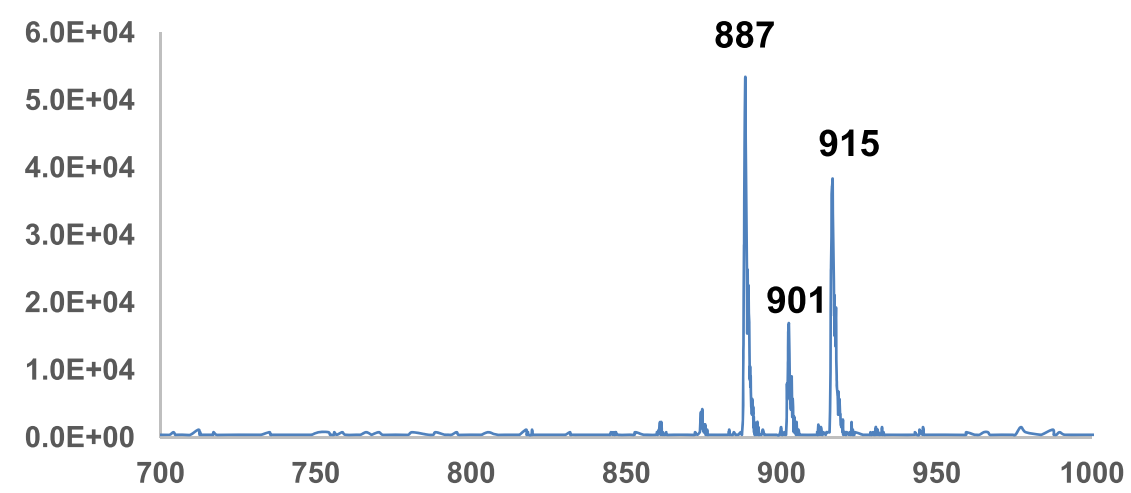

B.

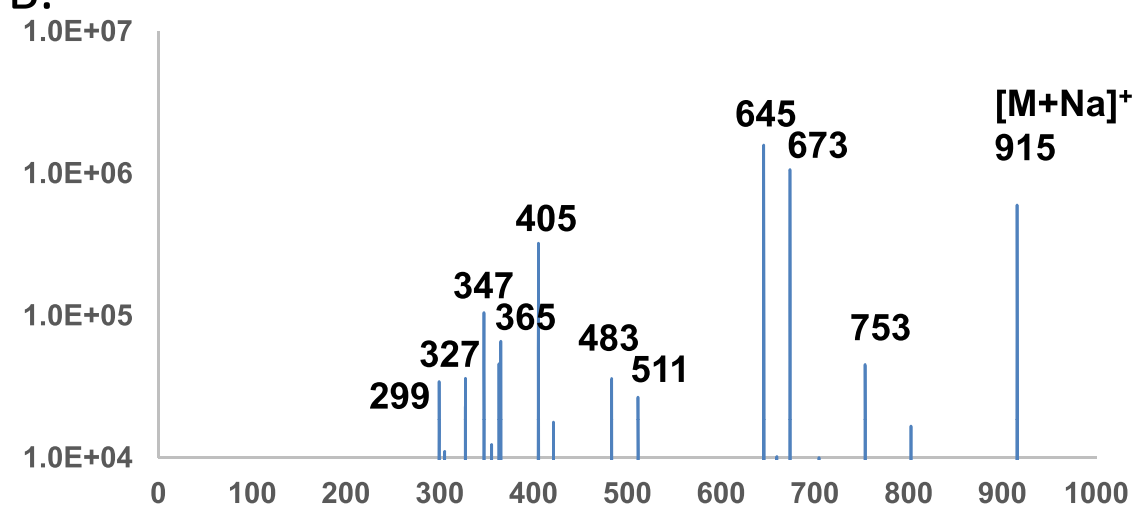

Figure 2. Lipid profiling and tandem mass spectra of sodiated DAG-GIc-GIc. Horizontal axis denotes $\mathrm{m} / \mathrm{z}$ values. Vertical axis denotes ion counts. DAG - diacylglycerol; Glc - glucose. A. Precursor scan for 347 amu sodiated diglucose dehydrate. B. MS/MS spectrum of sodiated (32:0) DAG-Glc-Glc (915 amu). 


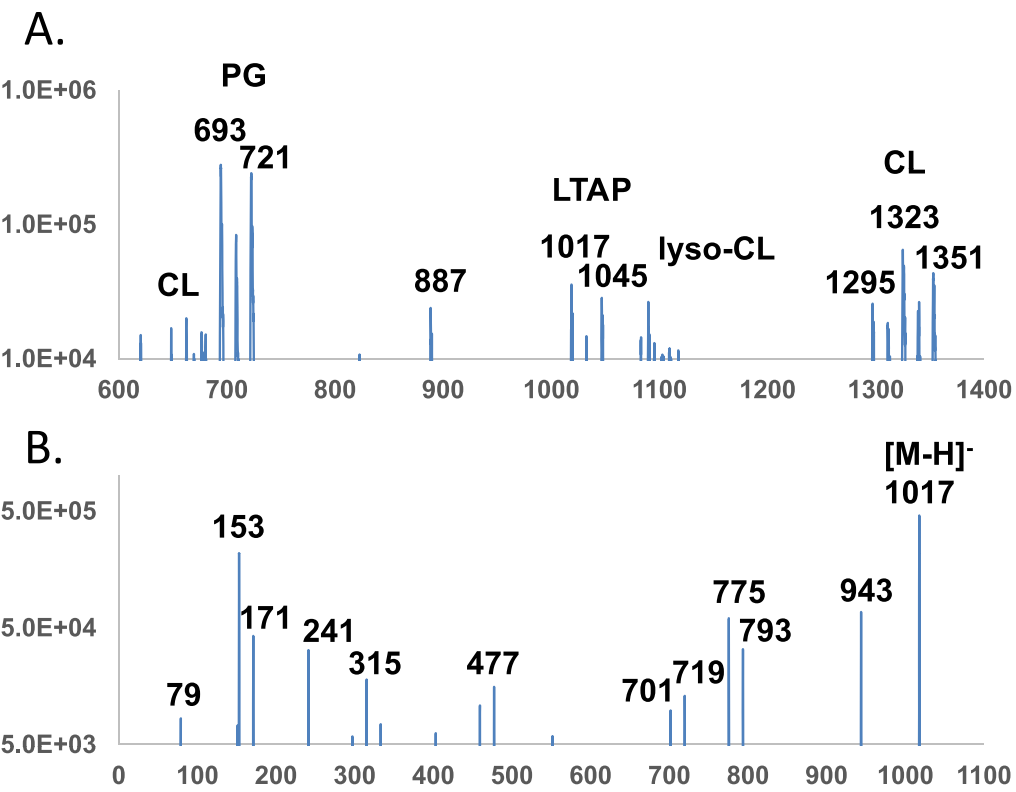

Figure 3. Lipid profiling and tandem mass spectra of deprotonated DAG-GIc-GIc-P-Gro lipoteichoic acid primer. Horizontal axis denotes $\mathrm{m} / \mathrm{z}$ values. Vertical axis denotes ion counts. DAG - diacylglycerol; PG - phosphatidylglycerol; P - phosphate; Gro - glycerol; Glc - glucose; LTAP - lipoteichoic acid primer; CL - cardiolipin. A. Precursor scan for 153 amu cyclo-glycerolphosphate anion. B. MS/MS spectrum of lipoteichoic acid primer (30:0) DAG-Glc-Glc-P-Gro (1017 amu).

\section{Table 2. Accurate masses of fragments from (30:0) DAG-GIc - -P-Gro lipoteichoic acid primer.}

\begin{tabular}{|l|l|l|l|}
\hline Observed mass & Calculated mass & Cleavage & Description \\
\hline 78.9589 & 78.9585 & $\mathrm{~g} \& \mathrm{i}$ & $\mathrm{P}-\mathrm{H}_{3} \mathrm{O}$ \\
\hline 152.9959 & 152.9953 & $\mathrm{~h}$ & $\mathrm{P}-\mathrm{GrO}-\mathrm{H}_{3} \mathrm{O}$ \\
\hline 171.0062 & 171.0059 & $\mathrm{~g}$ & $\mathrm{P}-\mathrm{GrO}-\mathrm{H}$ \\
\hline 241.2171 & 241.2169 & $\mathrm{~b}_{1}$ or $\mathrm{b}_{2}$ & $(15: 0) \mathrm{FA}-\mathrm{H}$ \\
\hline 315.0463 & 315.0481 & $\mathrm{f}$ & Glc-P-Gro $-\mathrm{H}_{3} \mathrm{O}$ \\
\hline 477.1002 & 477.1010 & $\mathrm{~d}$ & $\mathrm{Glc}_{2}-\mathrm{P}-\mathrm{GrO}-\mathrm{H}_{3} \mathrm{O}$ \\
\hline 701.3100 & 701.3051 & $\mathrm{~b}_{1} \& \mathrm{j}$ & $(15: 0) \mathrm{MAG}-\mathrm{Glc}_{2}-\mathrm{P}-\mathrm{H}_{3} \mathrm{O}$ \\
\hline 719.3195 & 719.3257 & $\mathrm{a}_{1} \& \mathrm{j}$ & $(15: 0) \mathrm{MAG}-\mathrm{Cl}_{2}-\mathrm{P}-\mathrm{H}$ \\
\hline 775.3502 & 775.3519 & $\mathrm{~b}_{1}$ & $(15: 0)$ lyso-form $-\mathrm{H}_{3} \mathrm{O}$ \\
\hline 793.3617 & 793.3625 & $\mathrm{a}_{1}$ & $(15: 0)$ lyso-form $-\mathrm{H}$ \\
\hline 943.5303 & 943.5399 & $\mathrm{j}$ & DAG-Glc $-\mathrm{P}-\mathrm{H}$ \\
\hline 1017.5769 & 1017.5770 & {$[\mathrm{M}-\mathrm{H}]$} & $(30: 0)$ LTAP $-\mathrm{H}$ \\
\hline
\end{tabular}

Note: The alphabetically labeled scissile bonds are shown in Figure 1D. FA - fatty acid; P - phosphate; Gro - glycerol; MAG - monoacylglycerol; DAG - diacylglycerol; Glc glucose; LTAP - lipoteichoic acid primer DAG-Glc - $_{2}$ - -Gro. Cleavage at $\mathrm{a}_{1}$ and $\mathrm{a}_{2}$, as well as at $b_{1}$ and $b_{2}$ produces fragments of identical sizes.

primers (Figure 1C), while the second cluster centered around the 1159 and $1187 \mathrm{amu}$ anions matched those of di-alanylated lipoteichoic acid primers (Figure 1D). There were no noticeable hits below $700 \mathrm{amu}$ or between 1200 and $1700 \mathrm{amu}$.

The overall mass of the 1088 amu anion matched that of (30:0) alanyl-lipoteichoic acid primer. The MS/MS spectra of the 1088 ion acquired with the QTRAP system at a collision energy of -90 electronvolts is shown in Figure $4 \mathrm{~B}$, and $\mathrm{m} / \mathrm{z}$ values of fragments are listed in Table 3. The 79, 153 and 171 amu ions corresponded to the putative glycerolphosphate backbone of this lipid. The dominant fatty acid ion at $241 \mathrm{amu}$ matched the expected (15:0) composition and its putative ester linkage to the lipid. The 88 amu ion implied a terminal ester-linked alanine. The $224 \mathrm{amu}$ ion 


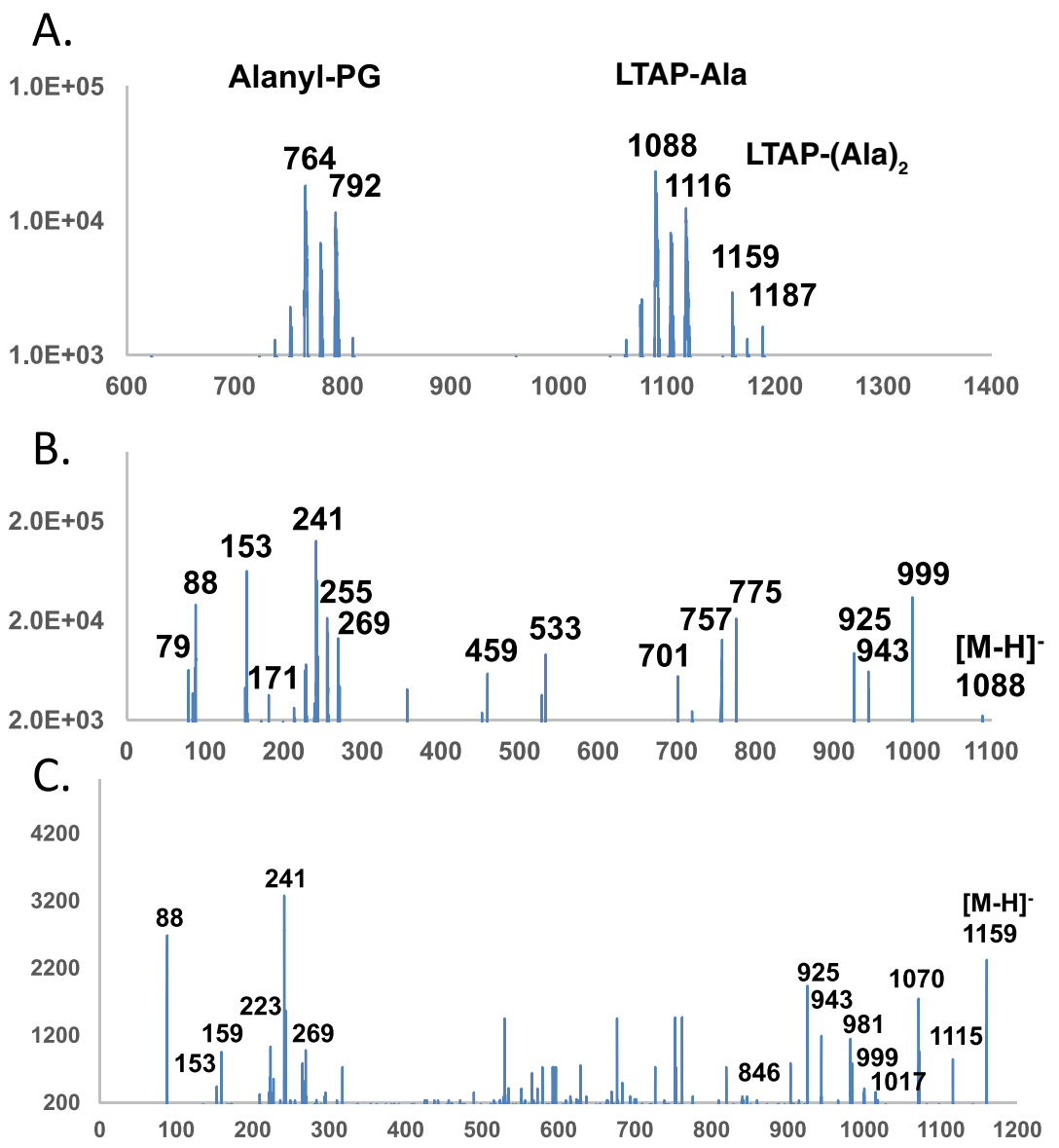

Figure 4. Lipid profiling and tandem mass spectra of mono- and dialanyl-derivatives of lipoteichoic acid primer. Horizontal axis denotes $\mathrm{m} / \mathrm{z}$ values. Vertical axis denotes ion counts. DAG - diacylglycerol; PG - phosphatidylglycerol; P - phosphate; Gro - glycerol; Glc - glucose; Ala - alanine; LTAP - lipoteichoic acid primer. A. Precursor scan for 88 amu [Ala-H]: B. MS/MS spectrum of mono-alanylated (30:0) lipoteichoic acid primer DAG-Glc-Glc-P-Gro-Ala (1088 amu). C. MS/MS spectrum of dialanylated (30:0) lipoteichoic acid primer DAGGlc-Glc-P-Gro-(Ala)2 (1159 amu).

corresponded to the dehydrated or cyclic form of the putative head group of alanylated glycerolphosphate. At the other end of the spectrum, the $999 \mathrm{amu}$ ion was likely due to the neutral loss of alanine (89 amu) from the 1088 molecular anion. The pair of ions at 925 and $943 \mathrm{amu}$ corresponded to the neutral loss of linear (163 amu) or cyclic (145 amu) alanyl-glycerol. In the mid-section of the spectrum, the 459 amu species corresponded to neutral losses of both DAG (540 amu) and alanine (89 amu), while the $533 \mathrm{amu}$ ion corresponded to neutral losses of both fatty acids $(2 \times 242=484 \mathrm{amu})$ and a dehydrated alanine (71 amu). Fragments at 757 and $775 \mathrm{amu}$ corresponded to the loss of one (15:0) fatty acid or ketene (242 or $224 \mathrm{amu}$ ) as well as alanine (89 amu). The smaller 701 and $719 \mathrm{amu}$ fragments corresponded to loss of one (15:0) fatty acid or ketene as well as cyclo-alanyl-glycerol (145 amu). Except for the absence of $701 \mathrm{amu}$ anion and the low-abundance $757 \mathrm{amu}$ anion in the Q-TOF-acquired spectrum, all fragments matched expected $\mathrm{m} / \mathrm{z}$ values within $0.004 \mathrm{amu}$. This $1088 \mathrm{amu}$ is most likely monoalanylated lipoteichoic acid primer.

The $\mathrm{m} / \mathrm{z}$ value of the $1159 \mathrm{amu}$ anion matched that of (30:0) di-alanyl-lipoteichoic acid primer. The MS/MS spectra of the 1159 ion acquired with the QTRAP system at a collision energy of -80 electronvolts is shown in Figure $4 \mathrm{C}$, and $\mathrm{m} / \mathrm{z}$ values of fragments are listed in Table 4. Due to the lower abundance of the 1159 anion, its MS/MS spectrum was noisier than those of the 1017 and 1088 anions. The spectrum shared 79, 88, 153, 171 and $241 \mathrm{amu}$ ions with that of the 1088 amu anion. Unexpectedly, a $159 \mathrm{amu}$ species corresponding precisely to deprotonated alanylalanine dipeptide was also observed. The mid-section of the spectrum did not reveal reoccurring ions in spectra collected at collision energies 10 electronvolts apart and therefore were likely noise due to the low abundance of this molecular ion. The whole head group of dialanylated glycerolphosphate was not observed. At the high end of the spectrum, an 846 amu fragment was probably generated by neutral losses of both (15:0) fatty acid (242 amu) and a cyclo-alanine (71 amu). The 925, 943 and 999 amu ions were in common with the fragments from the $1088 \mathrm{amu}$ anion of mono-alanylated lipoteichoic acid primer. A further dehydrated 981 amu ion was observed, which corresponded to neutral losses of two alanine molecules $(2 \times 89=178 \mathrm{amu})$. A larger $1017 \mathrm{amu}$ ion precisely matched that of (30:0) lipoteichoic acid primer. Another even larger 1070 amu ion corresponded to the $89 \mathrm{amu}$ neutral loss of one alanine 
Table 3. Accurate masses of fragments from (30:0) DAG-Glc 2 -P-Gro-Ala.

\begin{tabular}{|c|c|c|c|}
\hline Observed mass & Calculated mass & Cleavage & Description \\
\hline 78.9587 & 78.9585 & $g \& i$ & $\mathrm{P}-\mathrm{H}_{3} \mathrm{O}$ \\
\hline 88.0405 & 88.0399 & k & $\mathrm{Ala}-\mathrm{H}$ \\
\hline 152.9959 & 152.9953 & $g \& k$ & P-Gro $-\mathrm{H}_{3} \mathrm{O}$ \\
\hline 171.0062 & 171.0059 & $g \& 1$ & P-Gro - H \\
\hline 224.0316 & 224.0324 & $\mathrm{~h}$ & P-Gro-Ala $-\mathrm{H}_{3} \mathrm{O}$ \\
\hline 241.2170 & 241.2169 & $b_{1}$ or $b_{2}$ & $(15: 0) F A-H$ \\
\hline 459.0897 & 459.0904 & $d \& k$ & $\mathrm{GlC}_{2}-\mathrm{P}-\mathrm{GrO}-\mathrm{H}_{2} \mathrm{O}-\mathrm{H}_{3} \mathrm{O}$ \\
\hline 533.1236 & 533.1272 & $b_{1} \& b_{2} \& 1$ & dilyso-LTAP $-\mathrm{H}_{2} \mathrm{O}-\mathrm{H}_{3} \mathrm{O}$ \\
\hline$(701.4)$ & 701.3051 & $b_{1} \& j$ & $(15: 0)$ MAG-Glc $2-P-\mathrm{H}_{3} \mathrm{O}$ \\
\hline 719.3294 & 719.3257 & $a_{1} \& j$ & $(15: 0)$ MAG-Glc $2-P-H$ \\
\hline 757.3343 & 757.3414 & $b_{1} \& k$ & (15:0) lyso-LTAP $-\mathrm{H}_{2} \mathrm{O}-\mathrm{H}_{3} \mathrm{O}$ \\
\hline 775.3481 & 775.3519 & $b_{1} \& l$ & $(15: 0)$ lyso-LTAP $-\mathrm{H}_{3} \mathrm{O}$ \\
\hline 925.5254 & 925.5293 & i & (30:0) DAG-Glc $-\mathrm{P}-\mathrm{H}_{3} \mathrm{O}$ \\
\hline 943.5386 & 943.5399 & j & $(30: 0)$ DAG-Glc $c_{2}-\mathrm{P}-\mathrm{H}$ \\
\hline 999.5662 & 999.5661 & k & $(30: 0)$ LTAP $-\mathrm{H}_{3} \mathrm{O}$ \\
\hline 1088.6146 & 1088.6140 & {$[\mathrm{M}-\mathrm{H}]^{-}$} & (30:0) LTAP-Ala - H \\
\hline
\end{tabular}

Note: FA - fatty acid; P - phosphate; Gro - glycerol; MAG - monoacylglycerol; DAG diacylglycerol; Glc - glucose; Ala - alanine; LTAP - LTA primer DAG-Glc 2 -P-Gro. Values in parentheses were observed only with the low-accuracy 4000 QTRAP system.

\section{Table 4. Accurate masses of fragments from (30:0) DAG-Glc ${ }_{2}-\mathrm{P}-\mathrm{Gro}-(\mathrm{Ala})_{2}$.}

\begin{tabular}{|c|c|c|c|}
\hline Observed mass & Calculated mass & Cleavage & Description \\
\hline 88.0401 & 88.0399 & k or m & $\mathrm{Ala}-\mathrm{H}$ \\
\hline 152.9946 & 152.9953 & $g \& k \& n$ & P-Gro $-\mathrm{H}_{3} \mathrm{O}$ \\
\hline 159.0762 & 159.0770 & Figure $5 \mathrm{~A}$ & Ala-Ala-H \\
\hline 223.1704 & 223.1698 & & $(14: 2) F A-H$ \\
\hline 241.2166 & 241.2169 & $b_{1}$ or $b_{2}$ & $(15: 0) F A-H$ \\
\hline (846.4) & 846.3891 & $b_{1} \& l$ & $(15: 0)$ MAG-Glc - -P-Gro-Ala $-\mathrm{H}_{3} \mathrm{O}$ \\
\hline$(925.5)$ & 925.5293 & i & $(30: 0)$ DAG-Glc ${ }_{2}-\mathrm{P}-\mathrm{H}_{3} \mathrm{O}$ \\
\hline$(943.5)$ & 943.5399 & j & (30:0) DAG-Glc $\mathrm{C}_{2}-\mathrm{P}-\mathrm{H}$ \\
\hline$(981.6)$ & 981.5550 & $k \& m$ & $(30: 0)$ LTAP $-\mathrm{H}_{5} \mathrm{O}_{2}$ \\
\hline (999.5) & 999.5661 & $k \& n$ & $(30: 0) \mathrm{LTAP}-\mathrm{H}_{3} \mathrm{O}$ \\
\hline 1017.5774 & 1017.5770 & $I \& n$ & (30:0) LTAP - H \\
\hline 1070.6092 & 1070.6030 & k or m & (30:0) LTAP-Ala $-\mathrm{H}_{3} \mathrm{O}$ \\
\hline$(1115.7)$ & 1115.6610 & Figure 5B & (30:0) LTAP-Ala $2-\mathrm{CO}_{2}-\mathrm{H}$ \\
\hline 1159.6527 & 1159.6510 & {$[\mathrm{M}-\mathrm{H}]^{-}$} & (30:0) LTAP-Ala $2-\mathrm{H}$ \\
\hline
\end{tabular}

Note: The alphabetically labeled scissile bonds are shown in Figure 1. FA - fatty acid; P phosphate; Gro - glycerol; MAG - monoacylglycerol; DAG - diacylglycerol; Glc - glucose; Ala alanine; LTAP - LTA primer DAG-Glc ${ }_{2}-P-G r o$. Values in parentheses were observed only with the low-accuracy 4000 QTRAP system. 

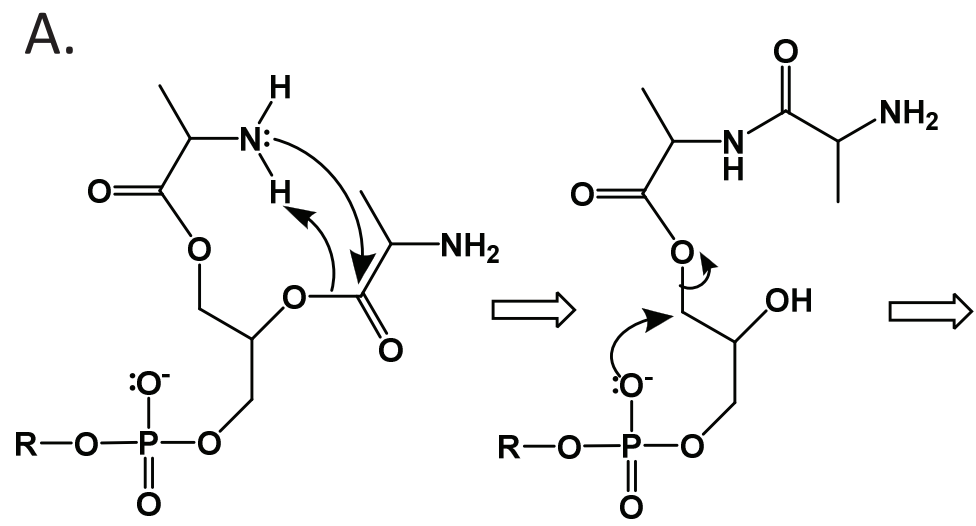<smiles>[R]OP1(=O)OCC(O)CO1</smiles>
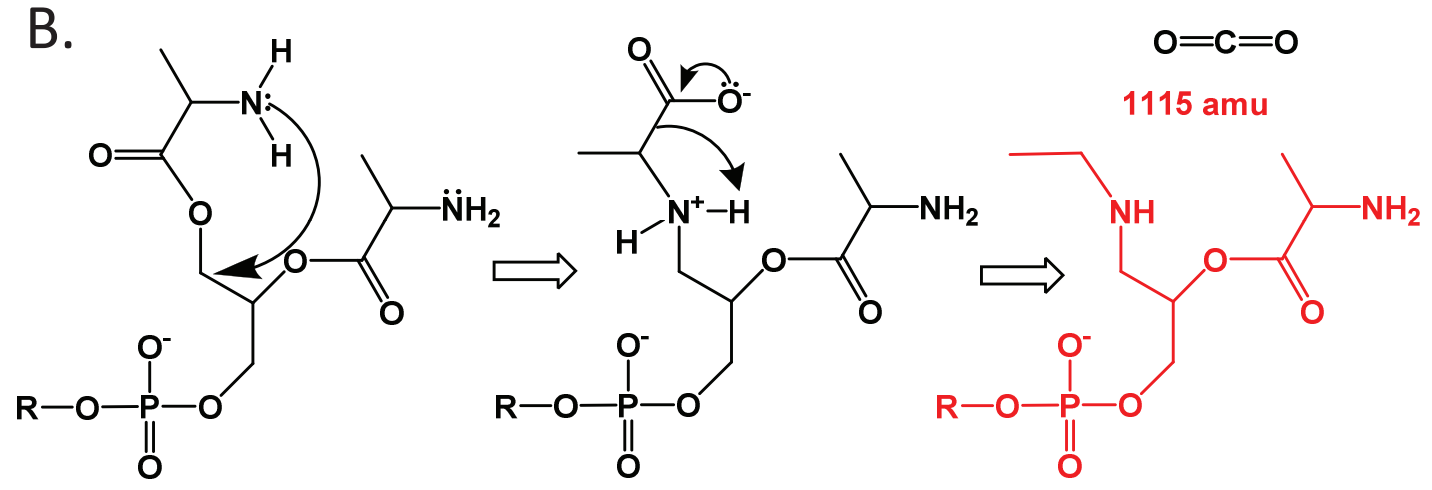

Figure 5. Putative two-step fragmentation reactions. The DAG-Glc-Glc part is shown as R. A. Rearrangement and fragmentation to produce the 159 amu dialanyl anion. B. Rearrangement and decarboxylation reactions which resulted in the neutral loss of the 44 amu $\mathrm{CO}_{2}$ and the 1115 amu fragment anion.

from the 1159 amu molecular anion. Surprisingly, a 1115 amu ion corresponding to a neutral loss of 44 amu was observed. As shown in Figure 5A, a two-step reaction may account for the formation of alanylalanyl-LTA primer and subsequent fragmentation into the 159 amu alanylalanine anion. An alternate reaction shown in Figure 5B may rearrange the putative bis-alanyl-LTA primer to expose a terminal carboxyl group in one of the two alanine residues, which could subsequently release the $44 \mathrm{amu} \mathrm{CO}_{2}$ and produce the $1115 \mathrm{amu}$ fragment anion. Due to the lack of any fragment ion corresponding to linear (313 amu) or cyclic (295 amu) bis-alanylglycerolphosphate, the result was not definitive on the location of two ester-linked alanine residues. Based on its similar fragmentation pattern to that of mono-alanylated LTA primer, this 1159 amu species is tentatively assigned as bis-alanyl-LTA primer (Figure 1D).

\section{Discussion}

Aminoacylated lipids play an apparent role in surface charge modulation of Gram-positive bacteria ${ }^{5}$. The least known part of charge modulation is arguably the D-alanylation pathway of lipoteichoic acids. The Bligh and Dyer method ${ }^{24}$ carried out at an icy temperature appeared to be essential for successful extraction of species that are almost certainly lipoteichoic acid primer and its monoand di-alanylated derivatives. My lab has recently observed that lysate of $B$. subtilis lipids contained predominantly D-alanine. Lysate of lipids in this study showed the expected predominance of D-alanine over L-alanine. The lipoteichoic acid primers were possibly esterized with D-alanine. The possible existence of the putative bis-alanylated lipoteichoic acid primer indicates that these species are unlikely to be hydrolyzed fragments of lipoteichoic acids since hydrolysis could only produce mono-alanylated derivative. Hydrolysis of lipoteichoic acid should also produce detectable amount of residue with more than one phosphoglycerol units attached to the lipid anchor, which was apparently lacking in the lipid extract. It also implies that lipoteichoic acid is unlikely to be transferred as D-alanyl-glycerolphosphate unit directly from D-alanyl-PG to the growing lipoteichoic acid chain by the LtaS polymerase as that would only produce mono-alanylated derivative. The observable abundance of lipoteichoic acid primer also appear to suggest that one of the four LtaS paralogs in B. subtilis ${ }^{28}$ may indeed act like LtaP primase in Listeria monocytogenes for the biosynthesis of lipoteichoic acid primer $^{29}$.

My lab has recently hypothesized that D-alanyl-PG may serve as the lipid intermediate for subsequent D-alanylation of teichoic acids. Taken together, a putative pathway is shown in Figure 6. It is known that DltA catalyzes the activation of D-alanine with the consumption of ATP and thioester formation with the D-alanyl 


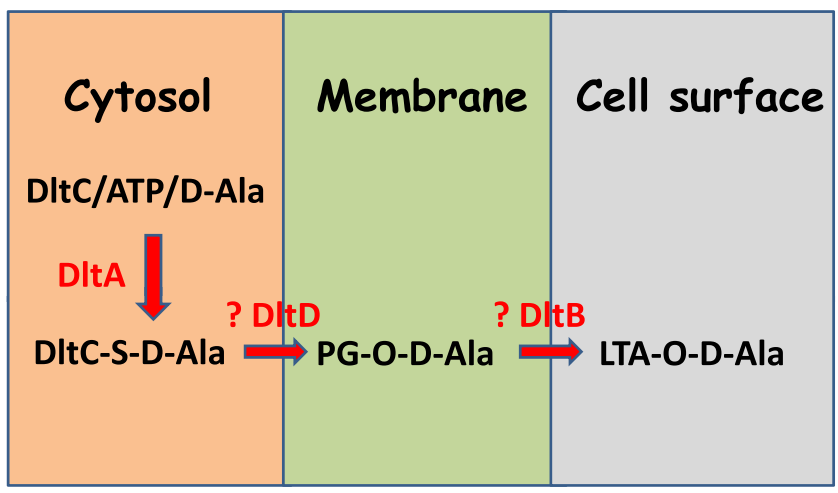

Figure 6. Putative D-alanylation pathway of lipoteichoic acid. DltA catalyzes the loading of thioester-linked D-alanine to the carrier protein DltC. DltC-carried D-alanyl group is further transferred to PG in the membrane by forming an ester bond. The putative enzyme for this process is DItD. PG-attached D-alanyl group is further transferred to LTA by transesterification. The putative enzyme for this latter process is DItB.

carrier protein DltC. It is possible either DltD or DltB - with the former being more likely based on the best available evidences that DltD binds DltC and has thioesterase activity ${ }^{22}$ - catalyzes the transfer of thioester-bound D-alanyl group to PG in the bacterial membrane by a thermodynamically spontaneous esterification reaction. The other one of the pair of Dlt proteins, most likely DltB, then catalyzes the transfer of D-alanyl group from the PG carrier to lipoteichoic acid by a transesterification reaction that can only reach equilibrium. This thermodynamic nature of this final transesterification reaction would enable the accumulation of a significant amount of the D-alanyl-PG intermediate, which is consistent with my lab's recent observation that alanyl-PG is somewhat abundant in lipids extracted from B. subtilis. Importantly, the diglucosyldiacylglycerol anchor, lipoteichoic acid primer, D-alanylated lipoteichoic acid primer as well as D-alanylated phosphatidylglycerol can be monitored in lipids extracted from wild-type and mutant cells of $B$. subtilis and aid in the full elucidation of the D-alanylation pathway of lipoteichoic acids.

\section{Data availability}

F1000Research: Dataset 1. Raw data for 'Alanylated lipoteichoic acid primer in Bacillus subtilis', Luo 2016. README.txt contains a description of the files, 10.5256/f1000research.8007.d113434 $4^{30}$

\section{Author contributions \\ YL conceived and carried out this study. \\ Competing interests \\ No competing interests were disclosed.}

\section{Grant information}

This work is supported by Saskatchewan Health Research Foundation Group Grant (2008-2010) and Phase 3 Team Grant (2010-2013) to the Molecular Design Research Group at University of Saskatchewan, a Natural Sciences and Engineering Research Council Discovery Grant (2010-2015) 261981-2010 to YL.

I confirm that the funders had no role in study design, data collection and analysis, decision to publish, or preparation of the manuscript.

\section{Acknowledgement}

I thank Ms. Deborah Michel for training and maintenance of SCIEX 4000 QTRAP system at the Core Mass Spectrometry Facility at the University of Saskatchewan. I also thank Mr. Paulos Chumala and Dr. George Katselis for tuning and operating the Agilent Q-TOF 6550 system.
1. Sohlenkamp C, Geiger O: Bacterial membrane lipids: diversity in structures and pathways. FEMS Microbiol Rev. 2016; 40(1): 133-59. PubMed Abstract | Publisher Full Text

2. Weidenmaier $\mathrm{C}$, Kristian SA, Peschel A: Bacterial resistance to antimicrobial host defenses--an emerging target for novel antiinfective strategies? Curr Drug Targets. 2003; 4(8): 643-9. PubMed Abstract | Publisher Full Text

3. Peschel A, Otto M, Jack RW, et al:: Inactivation of the dlt operon in Staphylococcus aureus confers sensitivity to defensins, protegrins, and other antimicrobial peptides. J Biol Chem. 1999; 274(13): 8405-10. PubMed Abstract | Publisher Full Text

4. Kristian SA, Lauth X, Nizet V, et al:: Alanylation of teichoic acids protects Staphylococcus aureus against Toll-like receptor 2-dependent host defense in a mouse tissue cage infection model. $J$ Infect Dis. 2003; 188(3): 414-23. PubMed Abstract | Publisher Full Text

5. Roy H: Tuning the properties of the bacterial membrane with aminoacylated phosphatidylglycerol. IUBMB Life. 2009; 61(10): 940-53. PubMed Abstract | Publisher Full Text | Free Full Text

6. den Kamp JA, Redai I, van Deenen LL: Phospholipid composition of Bacillus subtilis. J Bacteriol. 1969; 99(1): 298-303. PubMed Abstract | Free Full Text

7. Armstrong JJ, Baddiley J, Buchanan JG, et al.: Composition of teichoic acids from a number of bacterial walls. Nature. 1959; 184: 247-8. PubMed Abstract | Publisher Full Text

8. Neuhaus FC, Baddiley J: A continuum of anionic charge: structures and functions of D-alanyl-teichoic acids in gram-positive bacteria. Microbiol Mol Biol 
Rev. 2003; 67(4): 686-723

PubMed Abstract | Publisher Full Text | Free Full Text

9. Fischer W: Physiology of lipoteichoic acids in bacteria. Adv Microb Physiol. 1988; 29: 233-302.

PubMed Abstract | Publisher Full Text

10. Percy MG, Gründling A: Lipoteichoic acid synthesis and function in gram-positive bacteria. Annu Rev Microbiol. 2014; 68: 81-100.

PubMed Abstract | Publisher Full Text

11. Brown S, Santa Maria JP Jr, Walker S: Wall teichoic acids of gram-positive bacteria. Annu Rev Microbiol. 2013; 67: 313-36. PubMed Abstract | Publisher Full Text | Free Full Text

12. Hyyrylainen $\mathrm{HL}$, Vitikainen $\mathrm{M}$, Thwaite $\mathrm{J}$, et al.: D-Alanine substitution of teichoic acids as a modulator of protein folding and stability at the cytoplasmic membrane/ cell wall interface of Bacillus subtilis. J Biol Chem. 2000; 275(35): 26696-703. PubMed Abstract | Publisher Full Text

13. Perego $M$, Glaser $P$, Minutello $A$, et al.: Incorporation of $D$-alanine into lipoteichoic acid and wall teichoic acid in Bacillus subtilis. Identification of genes and regulation. J Biol Chem. 1995; 270(26): 15598-606. PubMed Abstract | Publisher Full Text

14. Kiriukhin MY, Neuhaus FC: D-alanylation of lipoteichoic acid: role of the D-alanyl carrier protein in acylation. J Bacteriol. 2001; 183(6): 2051-8. PubMed Abstract | Publisher Full Text | Free Full Text

15. Zimmermann S, Pfennig S, Neumann $P$, et al: High-resolution structures of the D-alanyl carrier protein (Dcp) DItC from Bacillus subtilis reveal equivalent conformations of apo- and holo-forms. FEBS Lett. 2015; 589(18): 2283-9. PubMed Abstract | Publisher Full Text

16. Du L $\mathrm{He} \mathrm{Y} \mathrm{Luo} \mathrm{Y.} \mathrm{Crystal} \mathrm{structure} \mathrm{and} \mathrm{enantiomer} \mathrm{selection} \mathrm{by} \mathrm{D-alanyl} \mathrm{carrier}$ protein ligase DItA from Bacillus cereus. Biochemistry. 2008; 47(44): 11473-80. PubMed Abstract | Publisher Full Text

17. Yonus H, Neumann P, Zimmermann S, et al:: Crystal structure of DltA. Implications for the reaction mechanism of non-ribosomal peptide synthetase adenylation domains. J Biol Chem. 2008; 283(47): 32484-91. PubMed Abstract | Publisher Full Text

18. Stachelhaus T, Mootz HD, Marahiel MA: The specificity-conferring code of adenylation domains in nonribosomal peptide synthetases. Chem Biol. 1999; 6(8): 493-505.

PubMed Abstract | Publisher Full Text

19. Hisanaga $\mathrm{Y}, \mathrm{Ago} \mathrm{H}, \mathrm{Nakagawa} \mathrm{N}$, et al:: Structural basis of the substrate-specific two-step catalysis of long chain fatty acyl-CoA synthetase dimer. J Biol Chem.
$2004 ; 279$ (30): 31717-26

PubMed Abstract | Publisher Full Text

20. Conti E, Franks NP, Brick P: Crystal structure of firefly luciferase throws light on a superfamily of adenylate-forming enzymes. Structure. 1996; 4(3): 287-98. PubMed Abstract | Publisher Full Text

21. Hofmann $\mathrm{K}$ : A superfamily of membrane-bound $O$-acyltransferases with implications for Wnt signaling. Trends Biochem Sci. 2000; 25(3): 111-2. PubMed Abstract | Publisher Full Text

22. Debabov DV, Kiriukhin MY, Neuhaus FC: Biosynthesis of lipoteichoic acid in Lactobacillus rhamnosus: role of DItD in D-alanylation. J Bacteriol. 2000; 182(10): 2855-64.

PubMed Abstract | Publisher Full Text | Free Full Text

23. Atila M, Luo Y: Profiling and tandem mass spectrometry analysis of aminoacylated phospholipids in Bacillus subtilis [version 1; referees: 1 approved, 2 approved with reservations]. F1000Res. 2016; 5: 121.

PubMed Abstract | Publisher Full Text | Free Full Text

24. Bligh EG, Dyer WJ: A rapid method of total lipid extraction and purification. Can J Biochem Physiol. 1959; 37(8): 911-917.

PubMed Abstract | Publisher Full Text

25. Tanaka S, Fujita Y, Parry HE, et al:: Mass++: A Visualization and Analysis Tool for Mass Spectrometry. J Proteome Res. 2014; 13(8): 3846-3853. PubMed Abstract | Publisher Full Text

26. Gidden J, Denson J, Liyanage R, et al.: Lipid Compositions in Escherichia coli and Bacillus subtilis During Growth as Determined by MALDI-TOF and TOF/ TOF Mass Spectrometry. Int J Mass Spectrom. 2009; 283(1-3): 178-184. PubMed Abstract | Publisher Full Text | Free Full Text

27. Fischer W, Mannsfeld T, Hagen G: On the basic structure of poly(glycerophosphate) lipoteichoic acids. Biochem Cell Biol. 1990; 68(1): 33-43. PubMed Abstract | Publisher Full Text

28. Gründling A, Schneewind O: Synthesis of glycerol phosphate lipoteichoic acid in Staphylococcus aureus. Proc Natl Acad Sci U S A. 2007; 104(20): 8478-83. PubMed Abstract | Publisher Full Text | Free Full Text

29. Webb AJ, Karatsa-Dodgson M, Gründling A: Two-enzyme systems for glycolipid and polyglycerolphosphate lipoteichoic acid synthesis in Listeria monocytogenes. Mol Microbiol. 2009; 74(2): 299-314. PubMed Abstract | Publisher Full Text | Free Full Text

30. Luo Y: Dataset 1 in: Alanylated lipoteichoic acid primer in Bacillus subtilis. F1000Research. 2016.

Data Source 


\section{Open Peer Review}

\section{Current Peer Review Status:}

\section{Version 2}

Reviewer Report 14 April 2016

https://doi.org/10.5256/f1000research.9104.r13311

(C) 2016 Sohlenkamp C. This is an open access peer review report distributed under the terms of the Creative Commons Attribution License, which permits unrestricted use, distribution, and reproduction in any medium, provided the original work is properly cited.

\section{Christian Sohlenkamp}

Center for Genomic Sciences, National Autonomous University of Mexico (UNAM), Cuernavaca, Mexico

I have no further objections to the indexing of the article.

Competing Interests: No competing interests were disclosed.

I confirm that I have read this submission and believe that I have an appropriate level of expertise to confirm that it is of an acceptable scientific standard.

Reviewer Report 13 April 2016

https://doi.org/10.5256/f1000research.9104.r13312

(C) 2016 Duda K. This is an open access peer review report distributed under the terms of the Creative Commons Attribution License, which permits unrestricted use, distribution, and reproduction in any medium, provided the original work is properly cited.

\section{Katarzyna Duda}

Junior Group of Allergobiochemistry, Research Center Borstel, Leibniz-Center for Medicine and Biosciences, Airway Research Center North (ARCN), Borstel, Germany

I am satisfied with the Author responses to my comments, and respective corrections.

Competing Interests: No competing interests were disclosed.

I confirm that I have read this submission and believe that I have an appropriate level of expertise to confirm that it is of an acceptable scientific standard. 


\section{Version 1}

Reviewer Report 24 March 2016

\section{https://doi.org/10.5256/f1000research.8616.r12358}

(C) 2016 Sohlenkamp C. This is an open access peer review report distributed under the terms of the Creative Commons Attribution License, which permits unrestricted use, distribution, and reproduction in any medium, provided the original work is properly cited.

\section{Christian Sohlenkamp}

Center for Genomic Sciences, National Autonomous University of Mexico (UNAM), Cuernavaca, Mexico

The present manuscript describes a mass spectrometric study of Bacillus subtilis lipids in which possible intermediates in the biosynthesis and D-alanylation of type I lipoteichoic acid are detected.

In general, the title is appropriate, and the abstract provides an adequate summary of the article. The conclusions are based on the raw data presented. My major critique is that the author actually does not show the presence of the pathway, he only detects molecular ions my MS that might be pathway intermediates. The other comments should be addressed to improve the manuscript. Comments:

1. Abstract: I think the word "possible" should be added, "Here I report the use of mass spectrometry in the identification of possible intermediate species...", because although that it is very probable that this is case, strictly speaking, it has not been shown.

2. Abstract: In the same sense, I think it is preferable to write "...D-alanyl-phosphatidyl glycerol should aid in..."

3. Introduction: It should be specified that the author refers to type I LTA.

4. Introduction: The first part of the introduction is very simplified, for example no lipid $A$ is mentioned, nor the modification it can suffer to make it less anionic. I suggest rewriting and improving this paragraph.

5. Figure 1 and 5: Double bonds should look identical in the figures.

6. Strictly speaking the authors don't show that it is D-alanine in the detected structures.

7. Results/Discussion: What does the author think is the explanation that the new species only can be detected after a cold extraction?

8. Methods: Why do the authors add sodium acetate to the growth medium before centrifugation of the culture?

9. Page 2, left column, middle paragraph: I think it should say "adenylylation" not "adenylation", because it is an AMP-transfer. 
10. Page 2, left column, middle paragraph: Instead of "The functionally uncharacterized DItB appears to be an integral membrane protein...", it would be better to write "is predicted to be...".

11. Page 2, left column, middle paragraph: It should say “O-acyltransferase", not "oacyltransferase"

12. In the legends to figures 3 and 4, it should say "acid" not "aicd".

13. Methods/Results: Why are the electronvolts sometimes "+" and sometimes "-_"

14. Tables 2 and 4: The abbreviation FA for fatty acid should be explained.

15. Page 8, left column, middle paragraph: The word "smaller" should be deleted.

16. I agree with reviewer one that $\mathrm{P}$ is probably a better abbreviation of the phosphate group.

Competing Interests: No competing interests were disclosed.

I confirm that I have read this submission and believe that I have an appropriate level of expertise to confirm that it is of an acceptable scientific standard, however I have significant reservations, as outlined above.

Author Response ( ) 28 Mar 2016

Yu Luo, University of Saskatchewan, Saskatoon, Canada

Christian Sohlenkamp, Center for Genomic Sciences, National Autonomous University of Mexico (UNAM), Mexico

The present manuscript describes a mass spectrometric study of Bacillus subtilis lipids in which possible intermediates in the biosynthesis and D-alanylation of type I lipoteichoic acid are detected.

In general, the title is appropriate, and the abstract provides an adequate summary of the article. The conclusions are based on the raw data presented. My major critique is that the author actually does not show the presence of the pathway, he only detects molecular ions my MS that might be pathway intermediates. The other comments should be addressed to improve the manuscript.

\section{YL: I appreciate Dr. Sohlenkamp's comments. I will incorporate changes as described} below in the revised version.

Comments:

1. Abstract: I think the word "possible" should be added, "Here I report the use of mass spectrometry in the identification of possible intermediate species...", because although that it is very probable that this is case, strictly speaking, it has not been shown. 
YL: I agree that its status as an intermediate has not been demonstrated so that "possible" should be added.

2. Abstract: In the same sense, I think it is preferable to write "...D-alanyl-phosphatidyl glycerol should aid in...".

YL: I agree.

3. Introduction: It should be specified that the author refers to type I LTA.

YL: I agree with both reviewers that type of LTA in B. subtilis should be specified.

4. Introduction: The first part of the introduction is very simplified, for example no lipid A is mentioned, nor the modification it can suffer to make it less anionic. I suggest rewriting and improving this paragraph.

YL: I will expand the introductory part. For instance, lipid A and lipopolysaccharide will be mentioned.

5. Figure 1 and 5: Double bonds should look identical in the figures.

YL: I will redraw the molecular figures to make the two lines in double bonds in the same thickness and redraw the glucosyl rings in chair conformation.

6. Strictly speaking the authors don't show that it is D-alanine in the detected structures. YL: I will revise the statements concerning D-alanylation. I will briefly report that the lipid lysate has much more D-alanine than L-alanine.

7. Results/Discussion: What does the author think is the explanation that the new species only can be detected after a cold extraction?

YL: It is possible that it is not stable at room temperature. I think the readers can explain this.

8. Methods: Why do the authors add sodium acetate to the growth medium before centrifugation of the culture?

YL: It is out of respect to previous publications that teichoic acid-linked D-alanine tend to be most stable under mildly acidic condition. It is also part of my effort to standardize protocols. As the $B$. subtilis grow dense, $\mathrm{pH}$ typically gradually raises from neutrality to $\sim 8.5$. Unlike lipid extraction under low temperature, adding sodium acetate before centrifugation was not a required procedure as unbuffered cells also produced similar amount of the reported lipid species.

9. Page 2, left column, middle paragraph: I think it should say "adenylylation" not "adenylation", because it is an AMP-transfer.

YL: Strictly speaking "adenylylation" is correct. It will be corrected.

10. Page 2, left column, middle paragraph: Instead of "The functionally uncharacterized DltB appears to be an integral membrane protein...", it would be better to write "is predicted to be...".

YL: I agree. 
11. Page 2, left column, middle paragraph: It should say “O-acyltransferase", not "oacyltransferase".

YL: Thanks for pointing out.

12. In the legends to figures 3 and 4 , it should say "acid" not "aicd".

YL: I was typing too fast.

13. Methods/Results: Why are the electronvolts sometimes "+" and sometimes "-".

YL: The sign of voltage values appears to follow the positive/negative mode of ionization. I had to specify the sign during the experiment.

14. Tables 2 and 4: The abbreviation FA for fatty acid should be explained.

YL: I will add this abbreviation.

15. Page 8, left column, middle paragraph: The word "smaller" should be deleted.

YL: I was emphasizing the relative ease of analyzing the smaller 1017 amu species than the larger 1045 amu species. As the sentence starts a paragraph, I agree it is better to remove "smaller".

16. I agree with reviewer one that $P$ is probably a better abbreviation of the phosphate group.

YL: I was trying to use 3-letter codes consistently. I will simplify it as "P".

Competing Interests: None.

Reviewer Report 25 February 2016

https://doi.org/10.5256/f1000research.8616.r12352

(c) 2016 Duda K. This is an open access peer review report distributed under the terms of the Creative Commons Attribution License, which permits unrestricted use, distribution, and reproduction in any medium, provided the original work is properly cited.

\section{Katarzyna Duda}

Junior Group of Allergobiochemistry, Research Center Borstel, Leibniz-Center for Medicine and Biosciences, Airway Research Center North (ARCN), Borstel, Germany

The work of Luo Y. describes an identification of the biosynthetic intermediates of the lipoteichoic acid utilizing mass spectrometrical approach.

Generally, the conclusions are based on the solid raw data, the title is appropriate, and the abstract provides subsequent summary of the article.

I have a few comments, which addressing can help to improve the manuscript:

1. In the abstract and introduction given description of LTA refers mainly to Type 1 of LTA. I 
would specify it, and in the introduction mention other types of LTA, that are structurally different (reviewed: Schneewind O., Missiakas D. J. Bacteriol. 2014, 196(6):1133.)

2. D-Alanylation of LTA 1 and 4 is indeed very common, for the reader of the paper would it be also of interest, to mention other LTA modifications.

3. The use of the sentence with the characterization of D- but not L-Alanine, is confusing, as to date all bacterial Ala is D-configured.

4. Fig. 1 - I suggest to draw sugars in chair conformation, and the double bonds of P- or COOgroups should be equally thick.

5. The given formula of glycerol is wrong - no double bond is present, better to use standard abreviation Gro, e.g. Gro-Glc-Glc (concerns also Table 1).

6. Phosphate groups are commonly abbreviated as P, not Pho. Table 1 - I would write LTA primer, not only LTA, otherwise confusing.

7. Page 4 . when describing peaks at 887 and 915 instead of using 30:0 and 32:0, please use 15:0+15:0, and 15:0+17:0, otherwise confusing.

8. Peak at 887 corresponds to $2 x$ Hex, Gro, $2 \times 15: 0, \mathrm{Na}$, so corresponds to sodiated (but not dehydrated - this word should be removed) linker (Figure 2A). The confusion with dehydrated or not was present a few times in the text (e.g. 753 amu represents loss of glucose and not dehydrated glucose).

9. On page 4 - the QTRAP spectra are shown in Fig 3 - Fig 4, not as in text Fig 2 - Fig 4

Competing Interests: No competing interests were disclosed.

\section{I confirm that I have read this submission and believe that I have an appropriate level of expertise to confirm that it is of an acceptable scientific standard.}

Author Response ( ) 03 Mar 2016

Yu Luo, University of Saskatchewan, Saskatoon, Canada

I appreciate Dr. Duda's time and comments. I will incorporate changes as described below in my response to Dr. Katarzyna Duda's suggestions.

1. In the abstract and introduction given description of LTA refers mainly to Type 1 of LTA. I would specify it, and in the introduction mention other types of LTA, that are structurally different (reviewed: Schneewind O., Missiakas D. J. Bacteriol. 2014, 196(6):1133.) YL: I will mention the review and specify that $B$. subtilis produces Type 1 lipoteichoic acid.

2. D-Alanylation of LTA 1 and 4 is indeed very common, for the reader of the paper would 
it be also of interest, to mention other LTA modifications.

YL: I will mention other types of lipoteichoic acid and that Type 1 and 4 lipoteichoic acids are commonly modified by D-alanine.

3. The use of the sentence with the characterization of D- but not L-Alanine, is confusing, as to date all bacterial Ala is D-configured.

YL: It is actually necessary to specify D-alanine. MprF in B. subtilis is known to catalyze the synthesis of L-alanyl-phosphatidylglycerol form L-alanyl-tRNA and phosphatisylglycerol.

4. Fig. 1 - I suggest to draw sugars in chair conformation, and the double bonds of P- or COO- groups should be equally thick.

YL: I will re-draw the structures with sugars in chair conformation, and revert to normal thickness in ChemDraw to make the double bonds equally thick.

5. The given formula of glycerol is wrong - no double bond is present, better to use standard abbreviation Gro, e.g. Gro-Glc-Glc (concerns also Table 1).

YL: The $\mathbf{4 0 5}$ amu species likely represents the structure shown with a double bond in Table-1. It was a common fragment for this group of sodiated cations of DAG-GIc-GIc, indicating both fatty acyl tails are lost. The $\mathbf{4 0 5}$ amu fragment corresponds to the neutral loss of both fatty acyl free radicals, or equivalently a ketene and a peroxyfatty acid. The double bond formation in the glycerol residue is a consequence of such neutral losses.

6. Phosphate groups are commonly abbreviated as P, not Pho. Table 1 - I would write LTA primer, not only LTA, otherwise confusing.

YL: I will rename Pho as $P$, and abbreviate LTA primer as LTAp.

7. Page 4. when describing peaks at 887 and 915 instead of using 30:0 and 32:0, please use 15:0+15:0, and 15:0+17:0, otherwise confusing.

YL: The (30:0) species was a mixture of (15:0-15:0), (14:0-16:0) and other diglucosyldiacylglycerol. I will state that (15:0-15:0) is the most abundant form in the mixture.

8. Peak at 887 corresponds to $2 x$ Hex, Gro, $2 \times 15: 0, \mathrm{Na}$, so corresponds to sodiated (but not dehydrated - this word should be removed) linker (Figure $2 \mathrm{~A}$ ). The confusion with dehydrated or not was present a few times in the text (e.g. 753 amu represents loss of glucose and not dehydrated glucose).

YL: Ester and glycosidic bonds, as well as peptide bonds, are synthesized with the net effect of dehydration. Dissociation of the molecular ion is not equivalent to the hydrolysis process in solution where a water molecule is added back to the broken parts. One or the other fragment of the molecular ion has to bare the consequence of dehydration incurred during the biosynthesis process. For instance, the $753 \mathrm{amu}$ fragment indeed represents the loss of a dehydrated glucose (162 amu) from the molecular ion of 915 amu. A neutral loss of 180 amu glucose would produce a fragment of 735 amu. It is true that the head group is not dehydrated in the lipid. However, the scan was indeed for precursor ions of the 347 amu dehydrated (-18 amu) and sodiated (+23 amu) diglucose (342 amu) fragment ion (342 - $18+23=347)$. 
9. $\quad$ On page 4 - the QTRAP spectra are shown in Fig 3 - Fig 4, not as in text Fig 2 - Fig 4 YL: They are indeed shown in Figures 2, 3 and 4.

Competing Interests: I do not have any competing interests that might be construed to influence your judgment of the article's or referee response's validity or importance.

The benefits of publishing with F1000Research:

- Your article is published within days, with no editorial bias

- You can publish traditional articles, null/negative results, case reports, data notes and more

- The peer review process is transparent and collaborative

- Your article is indexed in PubMed after passing peer review

- Dedicated customer support at every stage

For pre-submission enquiries, contact research@f1000.com 